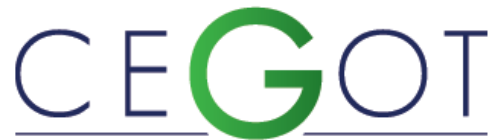

Centro de Estudos de Geografia e Ordenamento do Território
BUFFON, ELAIZ

Universidade Federal do Paraná, UFPR, Programa de PósGraduação em Geografia

81531-970, Centro Politécnico - Ed. João José Bigarella, 210, Curitiba/PR, Brasil

eambuffon@gmail.com

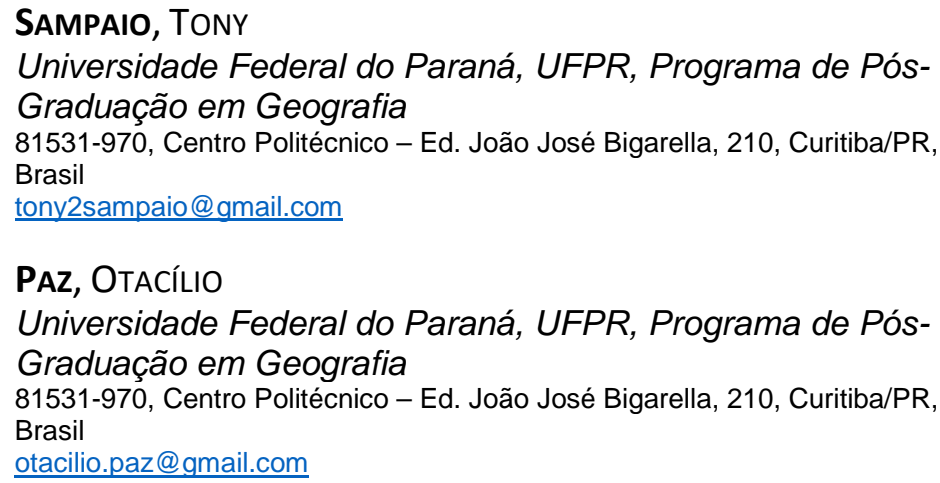

\title{
Veículo aéreo não tripulado (VANT) - aplicação na análise de inundações em áreas urbanas
}

Unmanned Aerial Vehicle (UAV) - application in the analysis of floods in urban areas

Referência: Buffon, Elaiz; Sampaio, Tony; Paz, Otacílio (2018). Veículo aéreo não tripulado (VANT) - aplicação na análise de inundações em áreas urbanas. Revista de Geografia e Ordenamento do Território (GOT), n. 13 (junho). Centro de Estudos de Geografia e Ordenamento do Território, p. 85-108, dx.doi.org/10.17127/got/2018.13.004

\section{RESUMO}

A avaliação do risco de inundação pode ser realizada considerando, de forma integrada, os processos resultantes de pressões físicas (perigo ambiental) e fragilidades (vulnerabilidades). Atualmente, as geotecnologias, em especial o VANT, permitem análises de problemas socioambientais em tempo real e com alta precisão. Nesta perspectiva, objetiva-se com o presente trabalho apresentar um encaminhamento metodológico para avaliação das áreas edificadas com risco de desastres ligado a inundação em áeas urbanas. Para isso, foram coletados dados primários na área de estudo (Campo Magro-Paraná, Brasil), por meio de VANT e trabalhos de campo, que, posteriormente, permitiram com auxílio de Sistema de Informação Geográfica construir um mapeamento síntese do risco de desastres. Os resultados indicam que a metodologia é de baixo custo e importante para as áreas desprovidas de imageamento em detalhe, e se mostrou eficiente como um sistema de apoio à decisão espacial frente à mitigação e prevenção dos desastres decorrentes de inundações.

Palavras-chave: Desastres, Risco, Vulnerabilidade, Inundação, Prevenção, Geotecnologias, VANT. 


\section{ABSTRACT}

The flood risk assessment can be carried out considering, in an integrated way, the processes resulting from physical pressures (hazard assessment) and weaknesses (vulnerabilities). Currently, the geotechnologies, in particular the UAV, allow analysis of environmental problems in real time and with high precision. In this perspective, the objective of this work is to present a methodological approach for the evaluation of the built-up areas potentially affected by urban floods. For this reason, primary data in the study area (Campo Magro-Paraná, Brazil) were collected through UAV and field work, which subsequently allowed, with the support of Geographic Information Systems, to build a synthesis mapping of disasters risk. The results indicate that the methodology is costeffective and important for the areas devoid of detailed imaging, and has proved to be efficient as a spatial decision support system for risk mitigation and prevention of the disasters caused by floods.

Keywords: Disasters, Risk, Vulnerability, Floods, Prevention, Geotechnologies, UAV.

\section{Introdução}

As cheias estão diretamente relacionadas com as características climáticas regionais e, assim, são consideradas fenômenos naturais. As alterações na bacia hidrográfica, advindas da ocupação e uso do solo pelo homem, interferem nas cheias e tendem a agravar as mesmas, tanto no nível de frequência como de intensidade, que podem desencadear inundações em áreas urbanas (WOLMAN, 1967; TUCCI, 2003).

As inundações consistem no processo de ocupação das planícies pelas águas, ou seja, é quando a água extravasa do canal fluvial (KOBIYAMA et al., 2006). Sendo assim, para originar um episódio de inundação é necessária a manifestação de um evento pluvial que, por sua vez, atrelado aos processos hidrológicos urbanos, promovem o extravasamento do rio que repercute espacialmente nas sociedades. Os impactos decorrentes das inundações são complexos e, em algumas situações, desestabilizam sistemas, com prejuízos sociais, econômicos e ambientais relevantes no contexto brasileiro (SILVEIRA, et al., 2009).

A ocorrência de inundações no Brasil é crescente a partir de 1960 (TOMINAGA, 2015). Tominaga (2015) apresenta, com base nos dados do EM-DAT (The International Disaster Database) de 2008, que o Brasil é um dos mais atingidos por inundações (TOMINAGA, 2015). Frente essa problemática, uma importante ação foi apresentada na década de 1990, 
quando foram definidos os objetivos para Redução de Desastres Naturais. Essa ação consistiu na implantação da Estratégia Internacional para Redução de Desastres - EIRD (International Strategy for Disaster Reduction - ISRD) que, posteriormente, propiciou a formação de macroprocesso da redução de risco de desastres.

No âmbito do Brasil, a partir de 2013, esse macroprocesso foi dividido em cinco processos inter-relacionados, a saber: prevenção, mitigação, preparação, resposta e recuperação (GREGORIO, et al., 2015). Os mesmos autores, apontam que as tecnologias podem auxiliar na concepção, execução e avaliação desses processos, e citam, como exemplo, que "o sensoriamento remoto tem se revelado uma ferramenta essencial para a gestão de risco de desastres naturais" (p.45).

Florenzano (2005) afirma que as geotecnologias ligadas ao Sensoriamento Remoto e os Sistemas de Informações Geográficas (SIG) estão cada vez mais interligados, apresentando potencial de aplicação em inúmeras áreas do conhecimento. Além disso são crescentes os avanços técnicos nos equipamentos, o que resultam em maior precisão e nível de detalhamento.

Dentre as novas plataformas para aquisição de dados em Sensoriamento Remoto, ganha destaque o Veículo Aéreo Não-Tripulado (VANT), popularmente conhecidos como Drones. Os VANTs apresentam vantagens técnicas e econômicas se comparados com os métodos tradicionais de aerolevantamento (LONGHITANO, 2010; GREGORIO et al., 2015). O uso de VANTs em estudos geográficos é recente no Brasil, mas se observa um grande potencial de aplicação dessa tecnologia em diversas análises geográficas.

As ortofotos obtidas com VANT (com GSD - Ground sample distance, variando entre 0,05 e 0,3 metros) constituem importante ferramenta para análise da problemática socioambiental na perspectiva de riscos e vulnerabilidades (BUFFON et al., 2017). Além da ortofoto outros produtos podem ser gerados, tais como: modelos digitais de superfície e de terreno (MDS e MDT, respectivamente). Segundo Feng et al., 2015, esses modelos (principalmente o MDS) são importantes em estudos de inundações urbanas, pois permitem melhor compreensão da dinâmica da água em ambientes edificados.

No entanto, mesmo com o baixo custo e elevada resolução atrelada aos produtos obtidos por VANTs, observa-se, ainda, que grande parte dos trabalhos que abordam análises 
ambientais em nível de detalhe utilizam dados provindos de levantamento Light Detection And Ranging - LIDAR (FENG et al., 2015; CIRILO et al., 2014; HAN e KIM, 2011; DANTAS, 2012; PEREIRA et al., 2013). Cabe destacar que o alto custo dessa tecnologia é o principal fator que reduz a disponibilidade dos dados em muitas áreas do território brasileiro. Neste sentido, os VANTs podem preencher essa lacuna.

Atualmente, muitos são os estudos disponíveis que realizaram propostas para avaliação de riscos, considerando a probabilidade de ocorrência de um fenômeno e o grau de perda potencial associado, ou seja, os impactos decorrentes da efetivação de um fenômeno no espaço. Autores como Dauphiné (2001), Rebelo (2010) e Cunha (2015), enfatizam teoricamente a abordagem de risco a partir da articulação dos índices de perigo (probabilidade de ocorrência) com os de vulnerabilidade (grau de fragilidade).

Neste viés, Gregorio et al., (2015, p.47) ressalta que "a análise dos cenários de risco de um sítio deve, com base nas ameaças previamente identificadas no local, simular situações capazes de provocar os desastres e buscar entender os processos e danos que poderiam ocorrer tendo como base as simulações". Assim, adota-se neste trabalho o conceito de risco como "à probabilidade de ocorrência de processos no tempo e no espaço, não constantes e não determinados, e à maneira como estes processos afetam (direta ou indiretamente) a vida humana" (CASTRO et al., 2005, p.12). Risco e perigo são conceitos associados, no entanto, conforme aponta Rebelo (2010) nem sempre o perigo consiste no risco, isso porque, por hora a manifestação do perigo pode ser controlado ou mesmo o fenômeno que simboliza o perigo pode apresentar um recuo.

Atrelado a esses conceitos, enfatiza-se o conceito de vulnerabilidade a partir da perspectiva apresentada por Cutter (1996) quando descreve que a vulnerabilidade do lugar compreende a vulnerabilidade ambiental (biofísica) que enfoca a probabilidade de exposição, e a social que evidencia a análise da probabilidade de consequências adversas. Outro conceito utilizado é o de desastre, que se refere ao "resultado de eventos adversos, naturais ou provocados pelo homem, sobre um ecossistema (vulnerável), causando danos humanos, materiais e/ou ambientais e consequentes prejuízos econômicos e sociais" (CASTRO, 1999, p.2). 
Embasado nessas considerações teóricas, propõe-se para o presente estudo, um encaminhamento metodológico que se sustenta na avaliação de risco como sendo "a combinação de probabilidade de ocorrência de um evento e suas consequências negativas" (UNISDR, 2009, p.25). Para isso, utiliza-se da perspectiva de perigo ambiental (elementos físicos do lugar) para representar a probabilidade de ocorrência de inundação, e da vulnerabilidade do lugar (elementos das estruturas das edificações e socioeconômicas da população), que quando cruzadas permitem mensurar um grau potencial de desastres associados à inundação em áreas edificadas.

Nesta perspectiva, este trabalho objetiva avançar nas discussões e propostas metodológicas associadas aos processos de prevenção frente ao risco de inundação em áreas urbanas. Apoia-se nas definições de prevenção e mitigação propostas por Castro et al. (1999) e EIRD (2009), que consideram a identificação e avaliação das áreas de risco, permitindo pensar e realizar ações de forma antecipada e, assim, auxiliar na mitigação (redução dos impactos).

A proposta metodológica aqui apresentada define quatro etapas essenciais: 1) A delimitação da área de estudo e a caracterização da vulnerabilidade do lugar a inundação; 2) Aquisição de dados espaciais, com auxílio de VANT e trabalho de campo, e posteriormente, o processamento em SIG; 3) Simulações de inundação e mapeamento das áreas de risco de inundação; e 4) Mapeamento do grau potencial de desastres associados à inundação em áreas edificadas.

\section{Caracterização da área de estudo}

\subsection{Enquadramento e descrição geral da área de estudo}

A área de estudo contempla parte da área urbana do município de Campo Magro, sendo seu recorte realizado com base em quatro critérios: 1) Localização periférica no contexto metropolitano (Aglomerado Urbano Metropolitano de Curitiba), inserida em uma cidade (Campo Magro) do aglomerado com maior taxa de crescimento urbano na última década (BUFFON, 2016); 2) Tamanho da área que viabilizou de modo adequado a aquisição de dados espaciais com VANT. 3) Heterogeneidade do índice de vulnerabilidade social a 
inundação por nível de desagregação de setores censitários (BUFFON et al., 2017); 4) Disponibilidade de estudo que avaliou e quantificou as condições de vulnerabilidade do lugar a inundação por nível de desagregação de quadras (BUFFON et al., 2017).

O grau de urbanização de Campo Magro em 2010 era de 78,7\%, sendo que população urbana era de 19.547 habitantes, tendo uma taxa de crescimento em relação ao ano de 2000 de 22,8\%, correspondendo a uma das maiores taxas em relação às demais cidades do aglomerado urbano metropolitano de Curitiba (BUFFON, 2016).

A área de estudo ocupa 49,51 ha e corresponde a três setores censitário do IBGE (Instituto Brasileiro de Geografia e Estatística), o que possibilitou realizar o levantamento de dados com o VANT em um tempo aproximado de 45 minutos, realizados a partir de três voos com duração média de 15 minutos. Dessa forma, a área de estudo é apresentada na figura 1, no que concerne a sua localização.

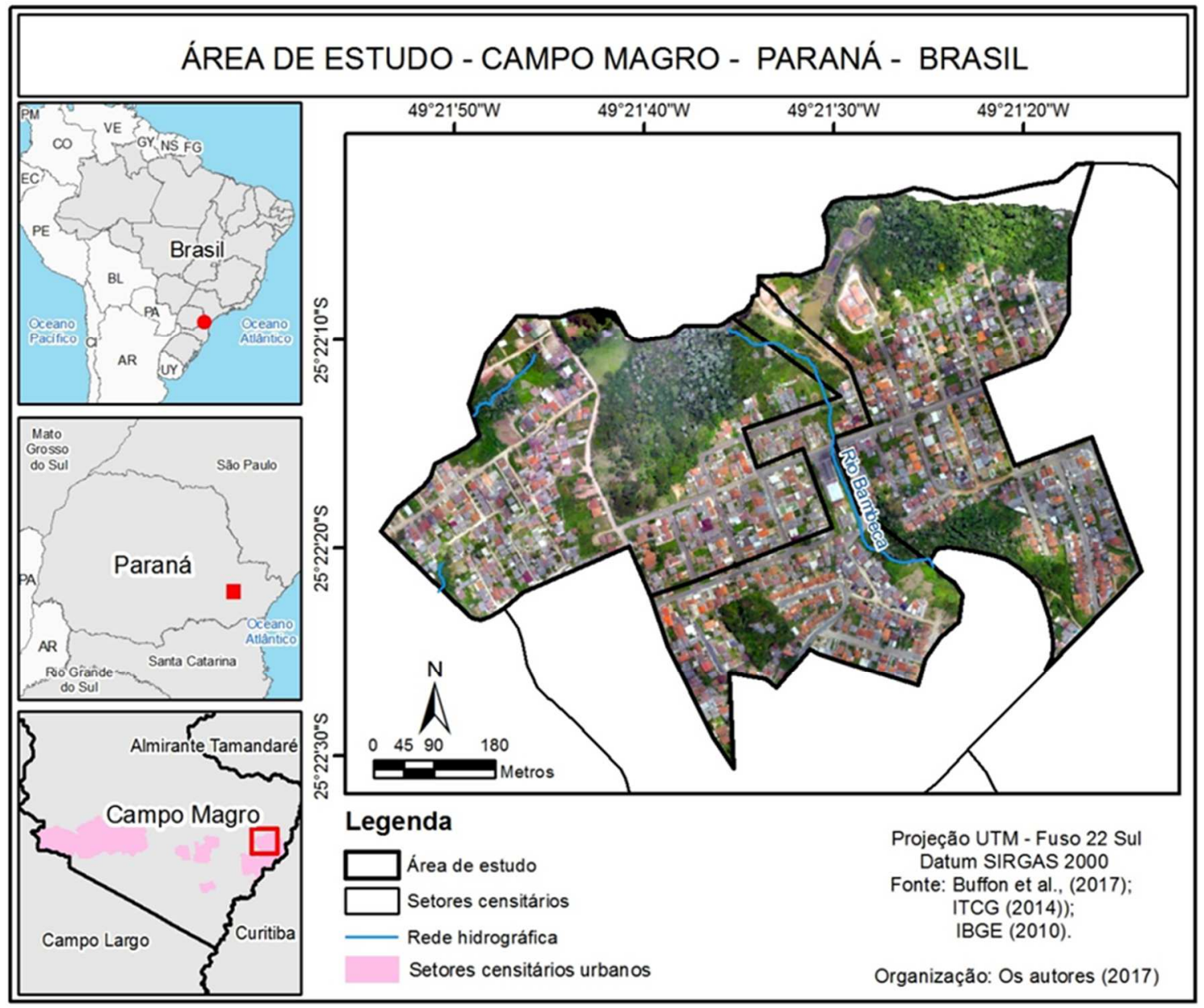

Figura 1: Campo Magro (PR): localização e ortofoto da área de estudo. 
Do ponto de vista físico-ambiental, a área de estudo localiza-se na bacia hidrográfica do Alto Iguaçu, mas especificamente na sub-bacia do Rio Passaúna (extensão territorial de $217 \mathrm{~km}^{2}$ ), sendo esse o principal rio e afluente pela margem direita do rio Iguaçu, que é o principal rio da bacia supracitada. No contexto específico da área de estudo, localiza-se o rio Bambeca que é afluente pela margem direita do rio Passaúna, e a oeste da área de estudo encontrase o rio Custódio, também, afluente do rio Passaúna.

As características climáticas da área de estudo, configura-se como mesotérmico brando, super úmido, sem estação seca (IBGE, 1998). A região em que a área de estudo se localiza caracteriza-se do ponto de vista geomorfológico como uma bacia de sedimentação (CANALI \& MURATORI, 1981), a pedologia é marcada pela presença de argissolo vermelho-amarelo.

\subsubsection{Caracterização da vulnerabilidade do lugar à inundação}

Para caracterizar a vulnerabilidade do lugar a inundação na área de estudo, esta pesquisa emprega a classificação proposta por Buffon et al. (2017), que utilizou às características sociais dos domicílios e dos moradores (esgotamento sanitário, coleta de lixo, abastecimento de água e renda), do ordenamento urbano (traçado do sistema viário, pavimentação e vegetação) e do ambiente (usos e cobertura da terra em APPs).

Da área total de estudo (abrangendo os 3 setores censitários), 30,6\% (15,17 ha) corresponde a vegetação arbórea, e 10,9\% (5,39 ha) é utilizado para arruamento, sendo que os restantes $58,5 \%$ (28,95 ha) correspondem as áreas com edificações e com vegetação arbustiva e herbácea, nas quais foi mapeada a vulnerabilidade. Dentro dessa porção da área total em que foi utilizado o mapeamento da vulnerabilidade do lugar à inundação, constatou-se a seguinte distribuição: muito baixo $(19,6 \%$ ou 9,69 ha), baixo $(2,4 \%$ ou 1,20 ha), médio a baixo corresponde $(5,45 \%$ ou 2,70 ha), médio a alto $(5,5 \%$ ou 2,72 ha), alto ( $13,7 \%$ ou 6,79 ha), e o muito alto ( $11,8 \%$ ou 5,9 ha) (Figura 2$)$. Esses valores enfatizam a heterogeneidade da área de estudo, com maior concentração nos graus de vulnerabilidade do lugar à inundação nas classes de muito baixo e alto, que empiricamente representam um evidente contraste nas condições de habitação desses dois graus de vulnerabilidade. 


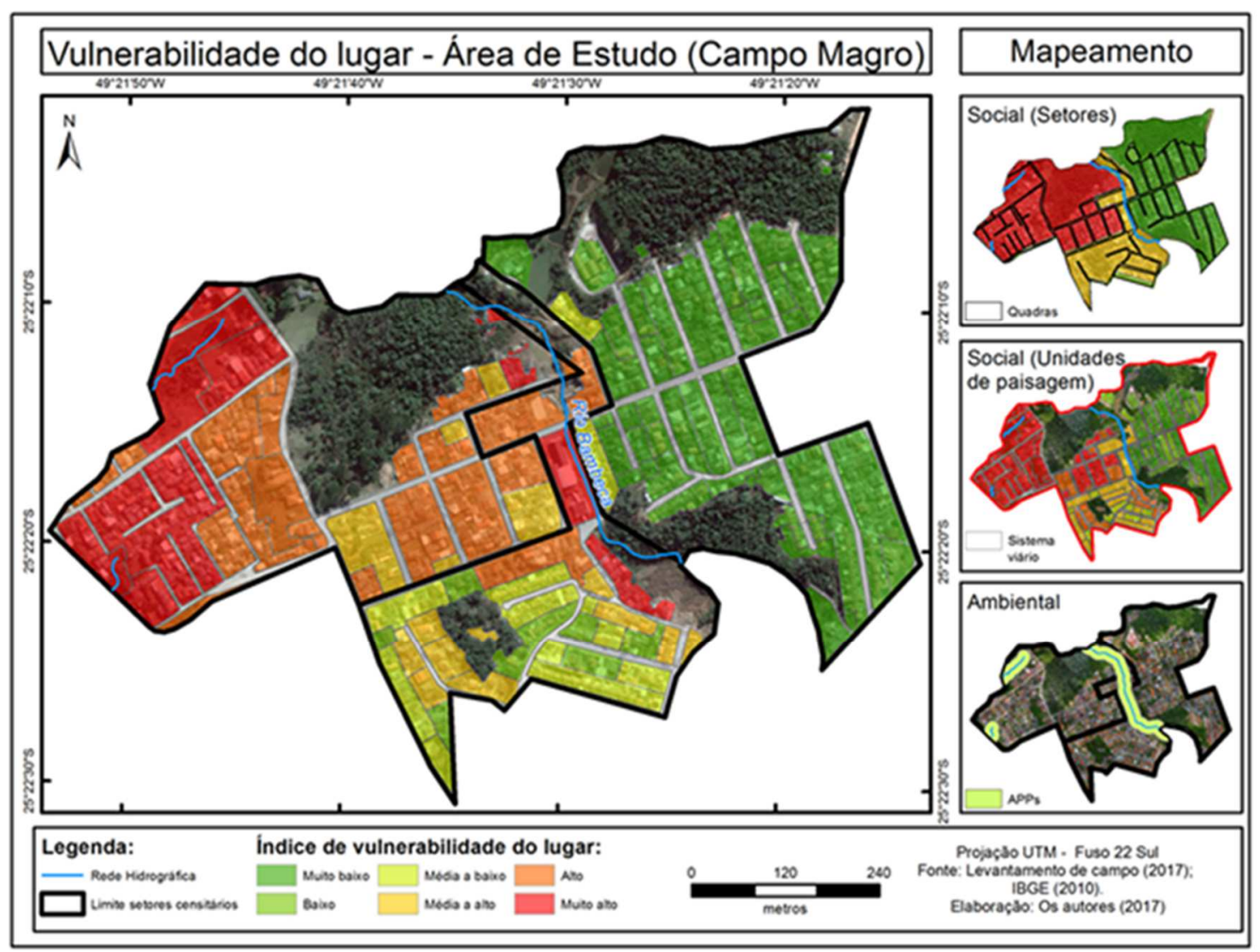

Figura 2: Área de estudo: mapeamentos que combinados formam o mapa composto de vulnerabilidade do lugar à inundação. Fonte: Buffon et al. (2017).

\section{Procedimentos metodológicos}

\subsection{A construção da base de dados}

Os dados necessários para desenvolvimento deste estudo foram levantados por meio de dois trabalhos de campo, o primeiro consistiu em obter dados com o VANT e foi realizado no dia 06 de fevereiro de 2017, enquanto que o segundo foi realizado no dia 09 de fevereiro de 2017 e visou a coleta de informações e registros fotográficos para definir as cotas de inundações.

\subsubsection{Dados de sensoriamento remoto}

Para o levantamento de dados de sensoriamento remoto foi utilizado um VANT do modelo Phantom 3 Professional, da DJI, disponibilizado pelo Departamento de Geografia da 
Universidade Federal do Paraná (UFPR). Os parâmetros e as linhas de um dos planos de voo são apresentados na figura 3.

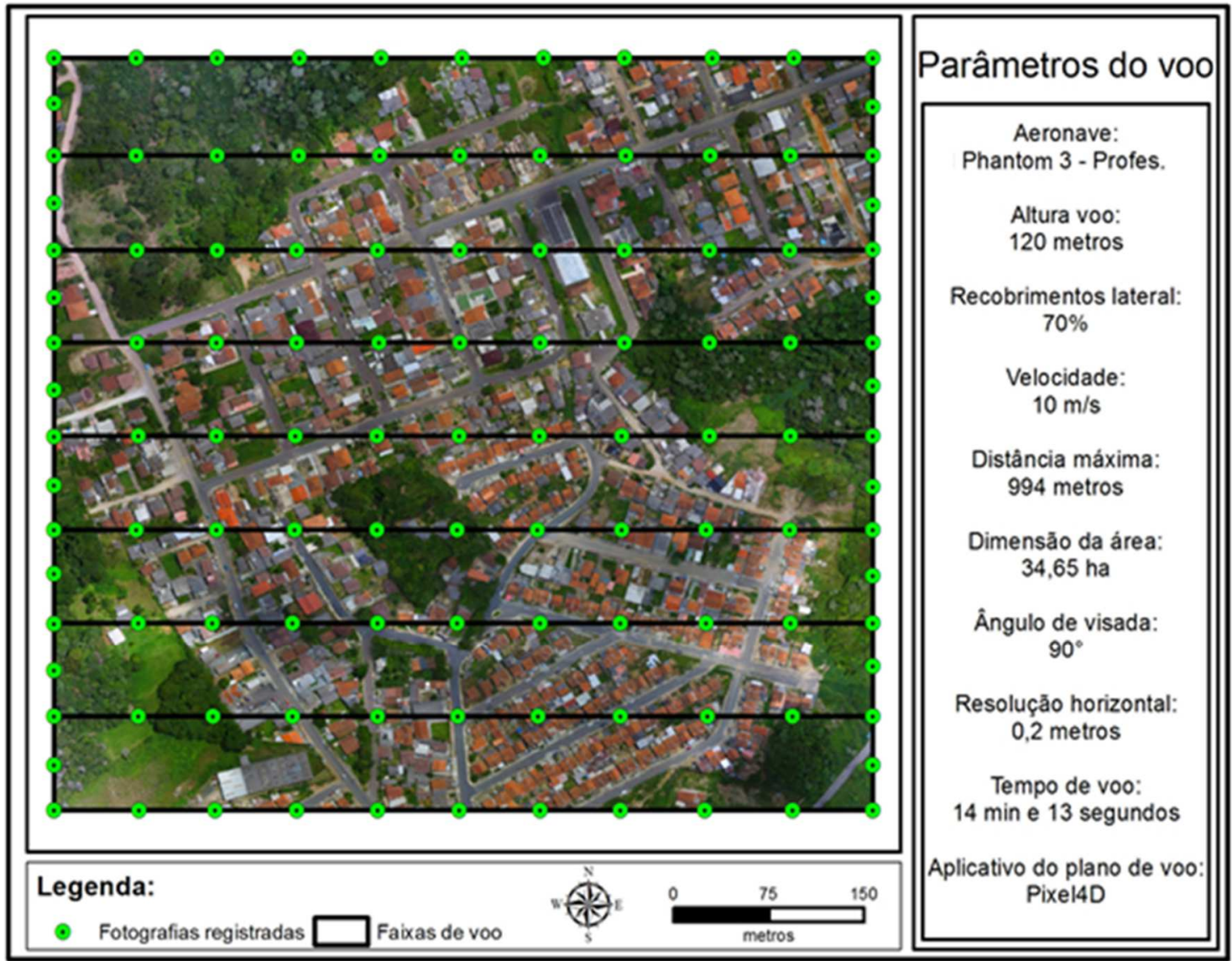

Figura 3: llustração de um dos três planos de voo realizado em campo.

Fonte: BUFFON et al., 2017.

O voo com o VANT, de acordo com a legislação brasileira, consistiu do uso de um sistema de Aeronave Remotamente Pilotada (RPA), formado pela RPA e pela estação de pilotagem (RPS) e pelo link de comando e controle a rádio. O voo foi acompanhado pela RPS, e foi classificado na categoria Pilotagem por Waypoint, ou seja, com um controle limitado da RPA. O plano de voo foi elaborado pelo aplicativo Pix4D Capture, com a aplicação de uma altura de 120 metros, tendo recobrimento lateral de $70 \%$.

O processamento das fotografias foi executado no software Agisoft PhotoScan. Foram aplicadas as rotinas para alinhamento, identificação dos pontos homólogos e geração da ortofoto, com os parâmetros apresentados na figura 4. É importante ressaltar que, optou-se por inserir os parâmetros em inglês em virtude desse ser o idioma utilizado no software Agisoft PhotoScan. 


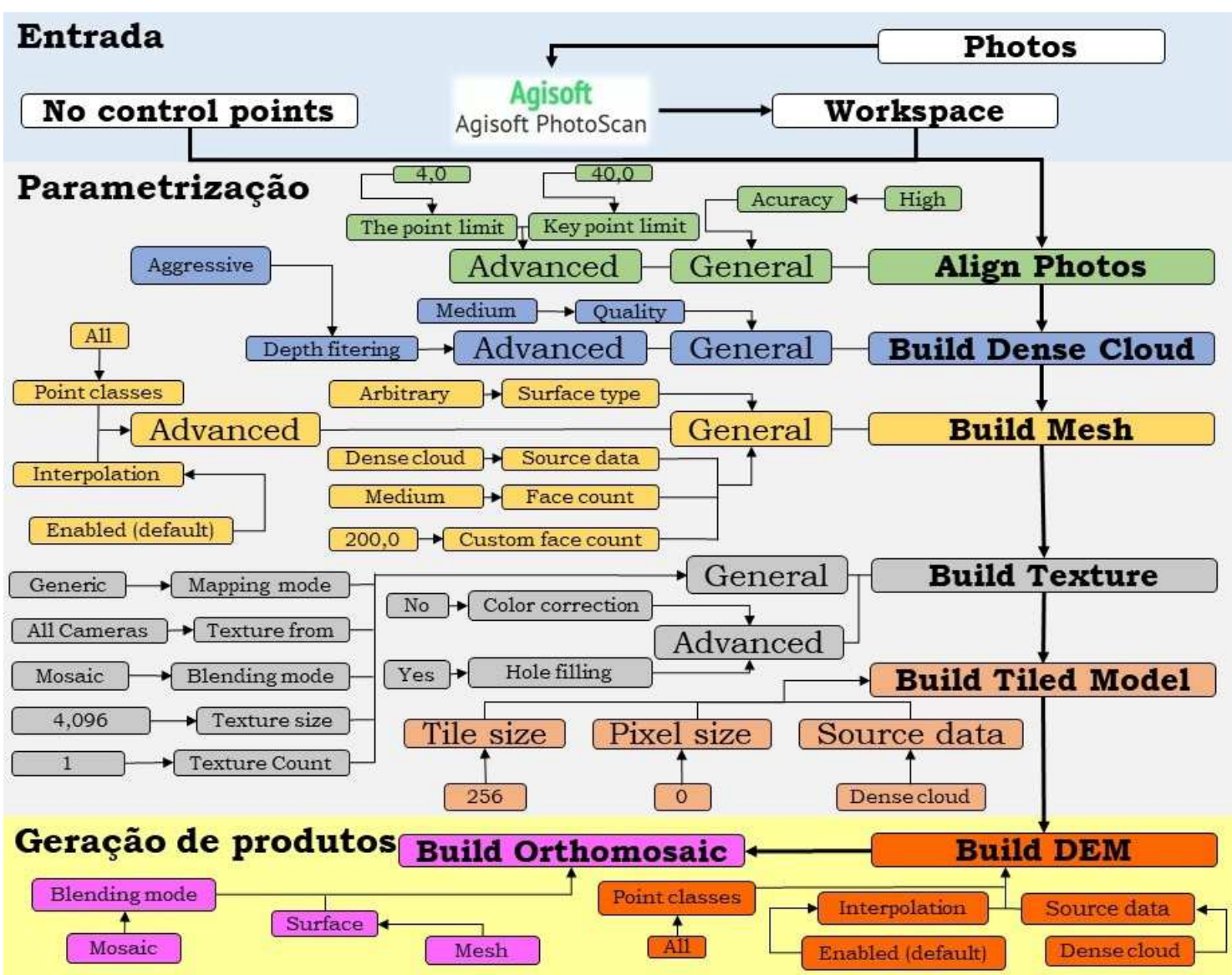

Figura 4: Rotinas e parâmetros adotados no processamento das imagens no software Agisoft PhotoScan. Elaboração: Os autores (2017).

O Modelo Digital de Superfície - MDS foi elaborado com resolução espacial de $0,2 \mathrm{~m}$ e a ortofoto com $0,05 \mathrm{~m}$. Como não foram utilizados pontos de controle, o erro altimétrico estimado para o Modelo Digital de Superfície é de 0,34m (RMSE). Este valor corresponde ao erro máximo observado em outros 22 levantamentos realizados com o mesmo equipamento em uma área próxima ao local de estudo e com uso de pontos de controle. A figura 5 apresenta a sequência de atividades realizadas para obter a ortofoto e o MDS. 


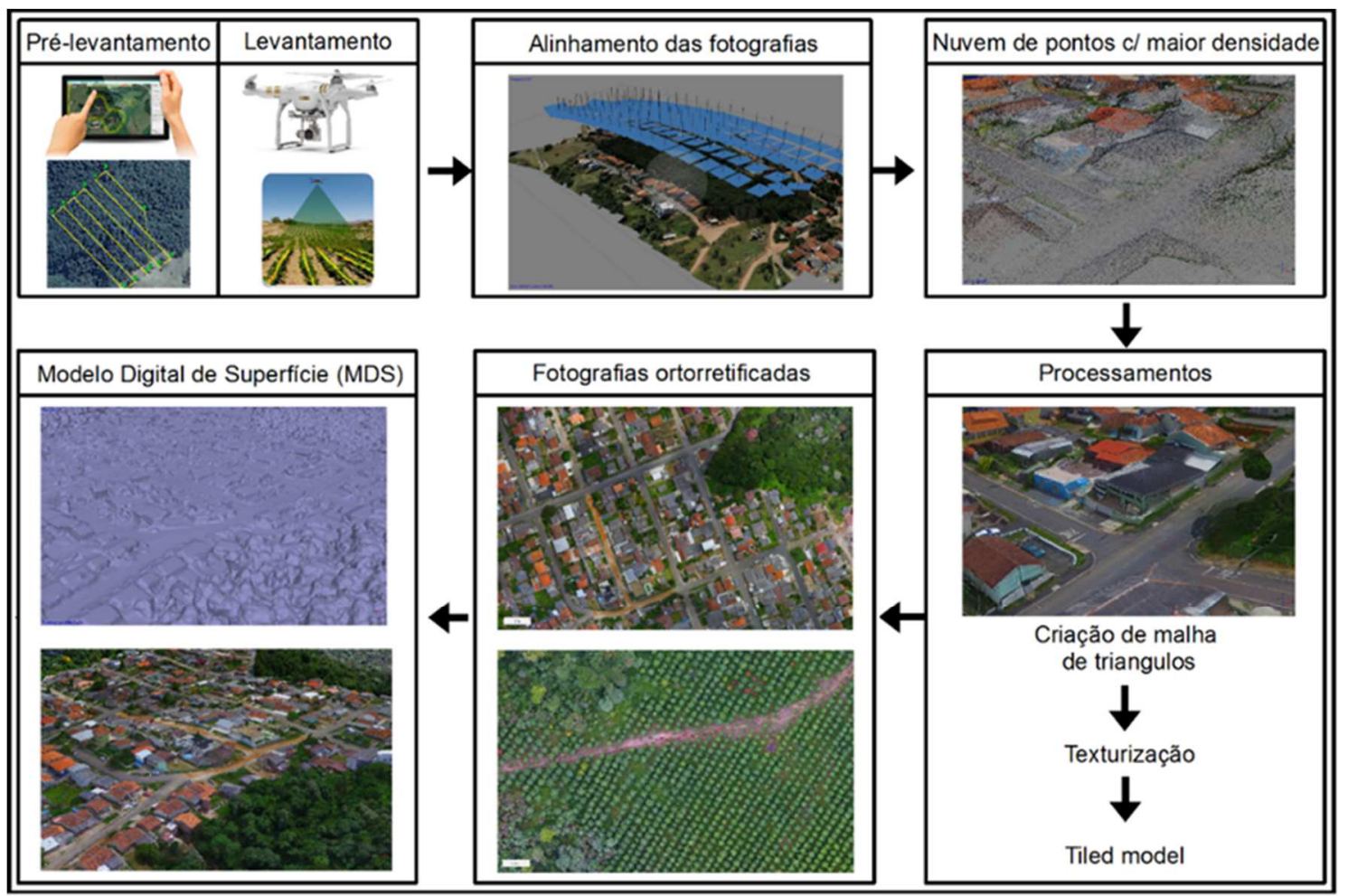

Figura 5: Organograma das operações realizadas para aquisição e processamentos dos dados levantados com VANT.

\subsubsection{Dados empíricos dos registros de episódios de inundações urbanas}

Os registros de episódios de inundações foram coletados in loco a partir de entrevista e levantamento fotográfico (conforme proposta de Justiniano (2009, p.187). A figura 6 apresenta a localização dos registros de campo. Foram levantados dados sobre: i) o tempo de moradia no local, ii) a ocorrência de inundações na residência, rua ou proximidade; iii) relatos sobre a realização de obras públicas de infraestrutura no bairro.

O levantamento de campo objetivou a aquisição de dados em áreas com distintas condições de vulnerabilidade do lugar a inundação (vide figura 2). Foram selecionados sete pontos para coleta de informações e registros fotográficos que servem de base para as simulações de inundações e, consequentemente, identificação das áreas de risco. 


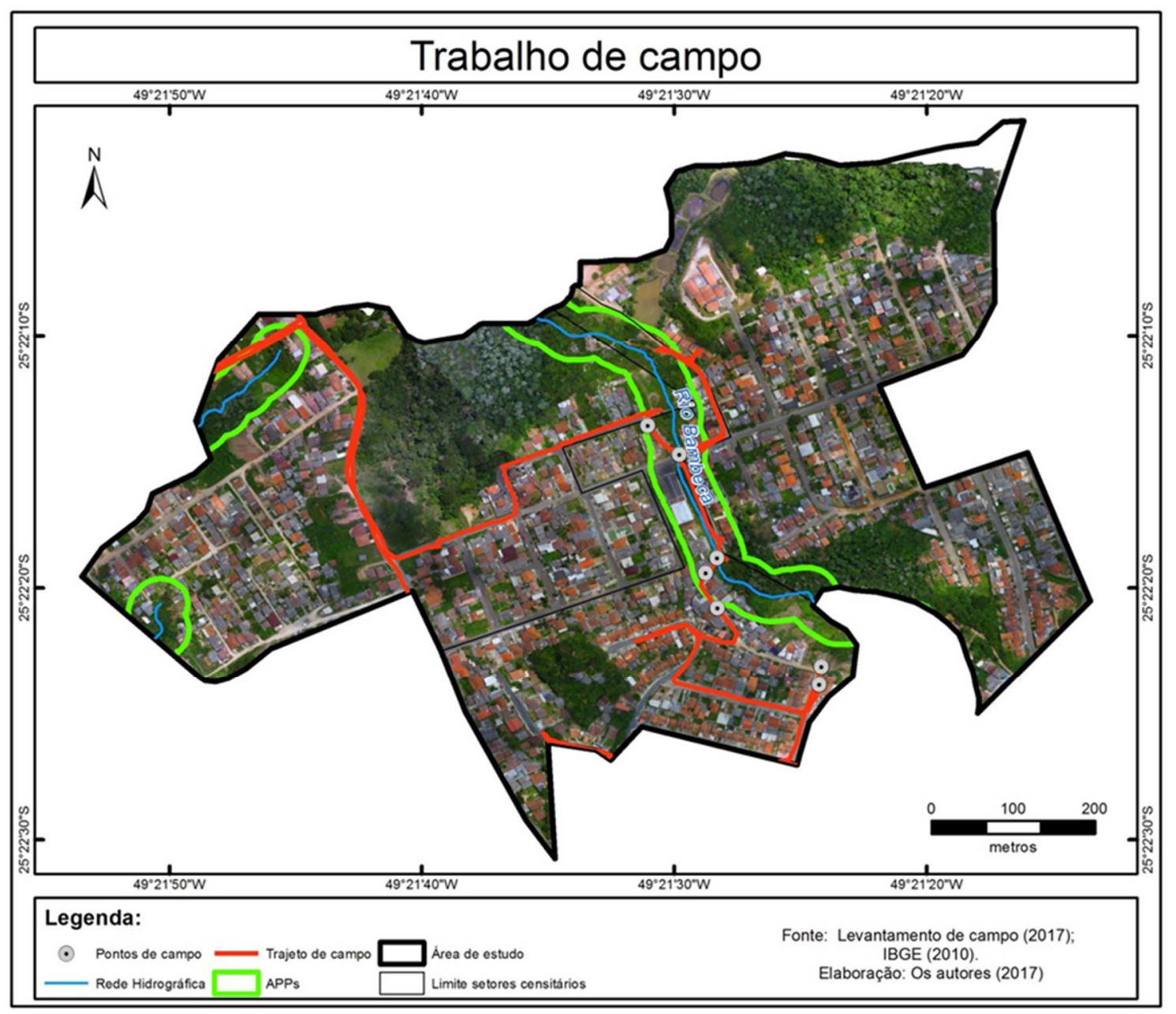

Figura 6: Trajeto do trabalho de campo e pontos de coleta de relatos.

\subsection{Métodos e técnicas para construção das simulações de inundações e mapeamento} das áreas de risco

As simulações das áreas que podem ser afetadas em episódios de inundações foram realizadas no software ArcGIS com a ferramenta reclass, versão 10.1, a partir do MDS gerado anteriormente através dos dados coletados com o VANT. Optou-se pelo emprego do MDS em razão do mesmo permitir uma análise em maior nível de detalhe em ambientes com a presença de obstáculos, característica fortemente presente no ambiente urbano, onde se encontram edificações (que podem apresentar mais de um pavimento), muros, meio fio, árvores, entre outros (FENG et al., 2015). Os critérios adotados para execução da ferramenta consistem na definição de valores numéricos de cotas de inundações. Esses valores foram embasados nos registros e relatos observados em campo que permitem constatar ocorrência de inundações em determinados pontos. 
Foram definidos quatro pontos para a verificação in loco da ocorrência de inundações. Cada ponto apresenta uma cota de inundação, que foram delimitadas com base nos relatos e registros fotográficos obtidos em campo. Considerou-se que a passagem de um episódio de enchente para inundação ocorre a partir do nível de elevação de 959 metros (caracterizada como cota inicial da inundação).

Assim, foram realizadas as seguintes simulações, considerando: 1 - cota de inundação com 1 metro acima do nível atual, 2: - cota de inundação com 3 metros acima do nível atual, 3 cota de inundação com 6 metros acima do nível atual, 4 - cota de inundação com 9 metros acima do nível atual. Nesse sentido, criou-se um cenário potencial de inundações que foi embasado nas simulações obtidas a partir da aplicação de cada uma das cotas. É importante ressaltar que, as áreas afetadas por inundações nas simulações, de acordo com relatos em campo já foram atingidas, sendo algumas simulações mais frequentes.

Ainda, com o propósito de auxiliar na avaliação das áreas de inundações, elaborou-se uma quantificação do uso e cobertura da terra a partir de seus valores relativos (em porcentagem), em cinco classes: 1) arruamento, 2) edificações, 3) solo exposto, 4) vegetação arbórea, 5) vegetação arbustiva/herbácea. Utilizando o mapeamento de uso e cobertura da terra, foi criado um tema de pontos, para demarcar cada uma das edificações existentes dentro da área de inundação (total das 4 simulações).

\subsection{Encaminhamentos metodológico para o mapeamento do grau potencial de desastres associados à inundação em áreas edificadas}

A determinação das classes do grau potencial de desastres associados à inundação foi embasada nos mapeamentos da vulnerabilidade do lugar e do risco de inundação, somente para as áreas com edificações. Utilizou-se 6 classes para caracterizar o grau potencial de desastres associados à inundação, a saber: muito baixo, baixo, médio a baixo, médio a alto, alto e muito alto. Essas classes foram obtidas a partir de um cruzamento em matriz vetorial, que considerou 6 classes de vulnerabilidade do lugar obtidos a partir do estudo de Buffon et al. (2017), e 3 classes de risco de inundação que correspondem as simulações de inundações, alto (área atingida pela cota de 3 metros), médio (área atingida pela cota de 6 metros) e baixo (área atingida pela cota de 9 metros). As classes do grau potencial de 
desastres associados à inundação $(G d a)$ é obtido a partir da seguinte fórmula: Gda $=(\mathrm{Vli} \pm$ Ri), sendo Vli a vulnerabilidade do lugar a inundação e Ri o risco de inundação. Assim, procedeu-se com o cruzamento, conforme é apresentado no quadro 1.

\begin{tabular}{|c|c|c|c|c|c|c|}
\hline \multirow{2}{*}{$\begin{array}{l}\text { Vulnerabilidade do } \\
\text { lugar a inundação }\end{array}$} & \multicolumn{4}{|c|}{ Perigo a inundação } & \multirow{2}{*}{\multicolumn{2}{|c|}{$\begin{array}{l}\text { Risco de desastres - } \\
\text { inundação }\end{array}$}} \\
\hline & Índice & Baixo & Médio & Alto & & \\
\hline Índice & \multicolumn{4}{|c|}{ CRUZAMENTO } & & Î́ndice \\
\hline Muito Baixo (MB) & \multirow{6}{*}{ 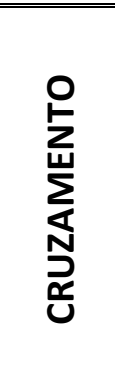 } & $\mathrm{MB}$ & $\mathrm{MB}$ & $B$ & \multirow{6}{*}{ 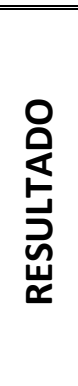 } & MB (muito baixo) \\
\hline Baixo (B) & & $\mathrm{MB}$ & $B$ & MaB & & B (baixo) \\
\hline Médio a Baixo (MaB) & & B & MaB & MaA & & $\begin{array}{l}\text { MaB (médio a } \\
\text { baixo) }\end{array}$ \\
\hline Médio a Alto (MaA) & & $\mathrm{MaB}$ & $\mathrm{MaA}$ & A & & MaA (médio a alto) \\
\hline Alto $(A)$ & & $\mathrm{MaA}$ & $A$ & MA & & A (alto) \\
\hline Muito Alto (MA) & & $\bar{A}$ & MA & MA & & MA (muito alto) \\
\hline
\end{tabular}

Quadro 1: Matriz de cruzamento dos mapeamentos de perigo e vulnerabilidade do lugar a inundação.

Elaboração: Os autores (2017).

\section{Resultados e discussão}

\subsection{Inundações em áreas urbanas de Campo Magro - PR: caracterização das áreas de risco e vulnerabilidade do lugar}

A construção do cenário de cotas de inundação (Figura 7) demonstrou que a simulação 1 (+ 1 metro) se restringe a área sem edificação. Os moradores, que vivem nas proximidades, relataram que são frequentes os casos de inundações, sendo que quando a água começa a atingir as edificações observa-se a simulação 2 (+ 3 metros) (Figura 6). As simulações 3 (+ 6 metros) e 4 (+ 9 metros) (Figura 7), correspondem as áreas na quais as inundações não são frequentes, mas que já aconteceram.

Em relação às ocorrências de inundações, os moradores relataram que, de modo frequente, as ocorrências de inundações estão associadas à ausência dos procedimentos de limpeza dos canais e rios, que reduzem a capacidade de escoamento da água em eventos pluviométricos extremos. De acordo com as informações levantadas, em um evento pluviométrico recente (17/10/2016) o cenário da simulação 3 se efetivou, sendo que foram afetadas diversas residências, conforme aponta a simulação no cenário. 


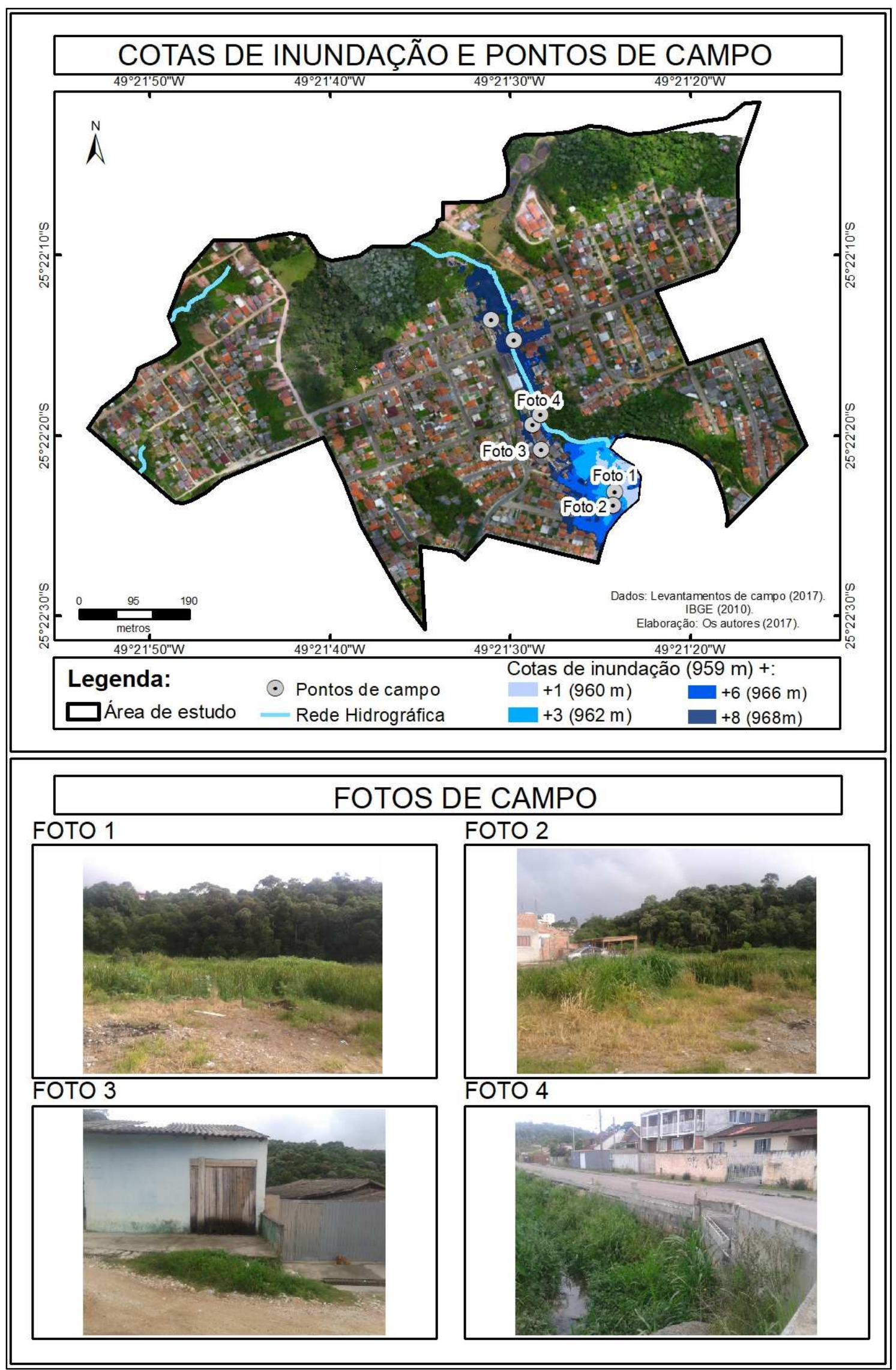

Figura 7: Área de estudo - Campo Magro: Cotas de inundação, pontos e fotos de campo. 
A figura 7 apresenta um cenário das áreas de inundações, a partir das 4 simulações, que foram classificadas de acordo com a frequência de ocorrência: simulação 1 (muito alto), simulação 2 (alto), simulação 3 (médio) e simulação 4 (baixo). A área total com risco de inundação ocupa $13,0 \%$ da área total de estudo, sendo que 4,9\% (0,24 ha) é identificada na simulação 1, 14,3\% (0,71 ha) na simulação 2, 25,9\% (1,29 ha) na simulação 3, e 55\% (2,74 ha) na simulação 4.

Para analisar o grau potencial de desastres associados à inundação, torna-se necessário conhecer os usos e cobertura da terra. Dentro dos 13,0\% supracitado (área com risco de inundação), 15,9\% é mapeada na classe de edificações, 65,1\% é coberta por vegetação arbórea ou arbustiva/herbácea, $12 \%$ é destinada para arruamento, e $7 \%$ é caracterizada por solo exposto (Quadro 2).

\begin{tabular}{|c|c|c|c|}
\hline Classe & Representação & Área (ha) & Área (\%) \\
\hline Arruamento & & 0,75 & 11,62 \\
\hline Edificações & & 1,03 & 15,90 \\
\hline Solo exposto & & 0,44 & 6,81 \\
\hline Vegetação arbórea & & 2,47 & 38,29 \\
\hline $\begin{array}{c}\text { Vegetação } \\
\text { arbustiva/herbácea }\end{array}$ & & 1,77 & 27,38 \\
\hline
\end{tabular}

Quadro 2: Área com risco de inundação: uso e cobertura da terra. Fonte: Levantamento de campo (2017).

Dentro classe de edificações foi possível quantificar a existência de 109 edificações que estão inseridas na área com risco de inundação. Desse total 104 são de uso predominante residencial (moradia). Considerando a sobreposição das edificações com as simulações de inundações, conclui-se que $109(67+28+14)$ edificações são afetadas na simulação 4, ou seja, todas as edificações existentes na área, $42(28+14)$ edificações são afetadas na simulação 3, 
14 edificações são afetadas na simulação 2, e na área afetada na simulação 1 não existe edificações.

Nesse sentido, adotou-se três categorias de risco de inundação em edificações, sendo essas: alto (todas as edificações existentes na área atingida pela simulação 2), médio (todas as edificações existentes na área atingida pela simulação 3 e, que não pertencem a área da simulação 2), e baixo (todas as edificações existentes na área atingida pela simulação 4, e que não pertencem as áreas da simulação 2 e 3) (Figura 8).

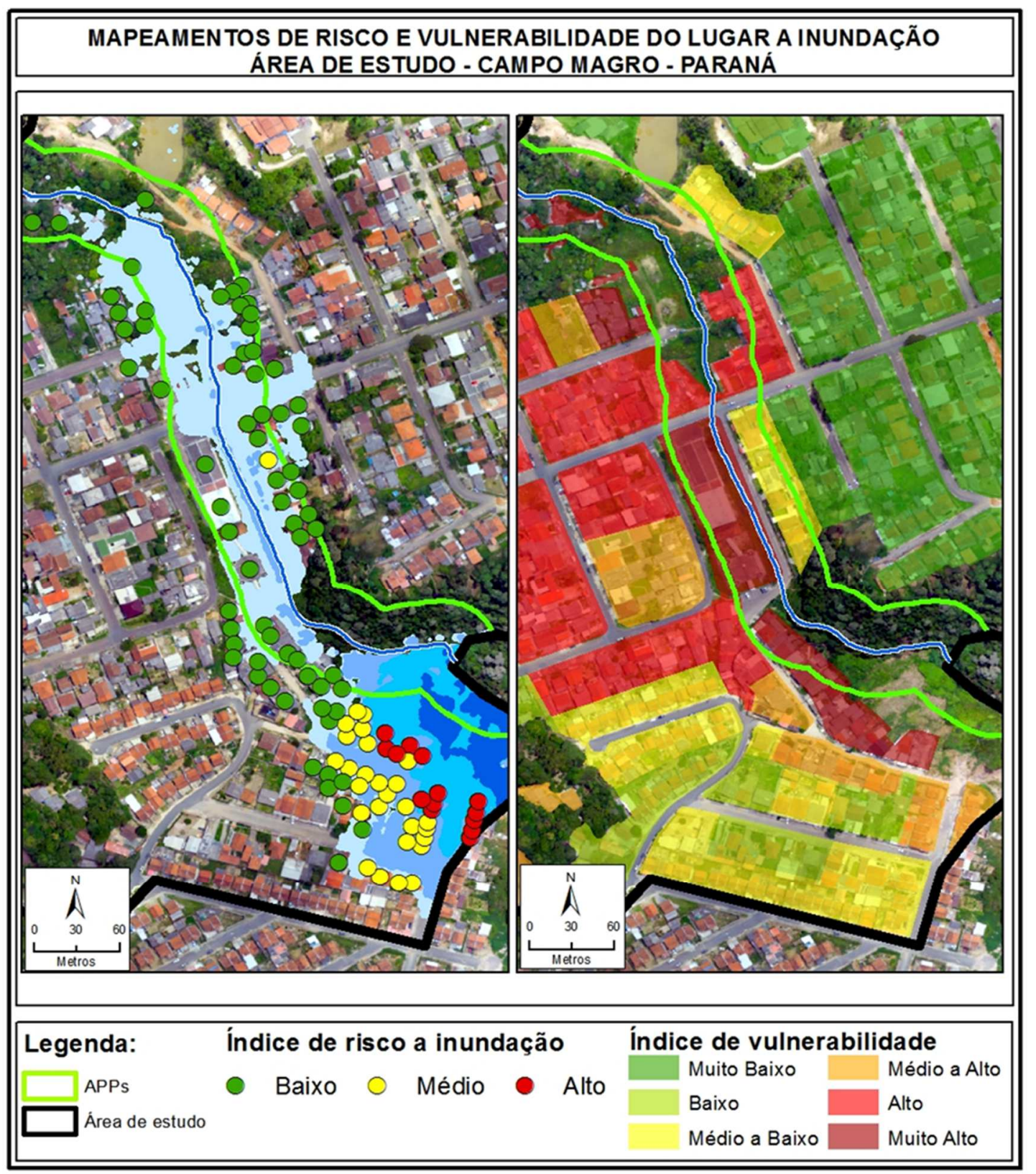

Figura 8: Mapeamentos utilizados na matriz de cruzamento para obtenção do grau potencial de desastres associados à inundação. 
Apenas uma edificação dentre todas que são identificadas com risco de inundações nas categorias alto e médio está inserida dentro da área de APP do rio Bambeca (Figura 8). Esse aspecto, denota que não é possível considerar a APP em sua integralidade como uma área de alto risco a inundação. No entanto, mesmo em áreas de APP com baixo risco de inundação, observou-se que a vulnerabilidade é caracterizada, predominantemente, por índices de alta e muito alta (Figura 8). Considerando que risco e vulnerabilidade estão diretamente associados em contextos de desastres, levantou-se a necessidade de analisar o grau potencial de desastres associados à inundação em áreas edificadas, resultante do cruzamento das condições de risco de inundação (probabilidade de ocorrência de um perigo) e vulnerabilidade a inundação (condições sociais e ambientais).

\subsection{Avaliações do grau potencial de desastres associados à inundação em área urbana edificada}

O resultado do cruzamento das classes de risco e vulnerabilidade do lugar à inundação permitiu observar uma configuração espacial segregada do risco alto e muito alto do grau potencial de desastres associados à inundação (Figura 9). São identificados os seguintes números de edificações por classes do grau potencial de desastres associados à inundação: 12 edificações com grau potencial de muito alto (nenhuma dentro da área de APP); 33 edificações com alto (13 edificações estão dentro da APP); e 34 com médio a alto (11 edificações estão dentro da APP) (Figura 9). No que se refere as classes do grau potencial de médio a baixo, baixo e muito baixo, os totais de edificações mapeadas foram os seguintes, respectivamente: 8 (1 na APP), 17 (11 em APP) e 5 (Figura 9). 


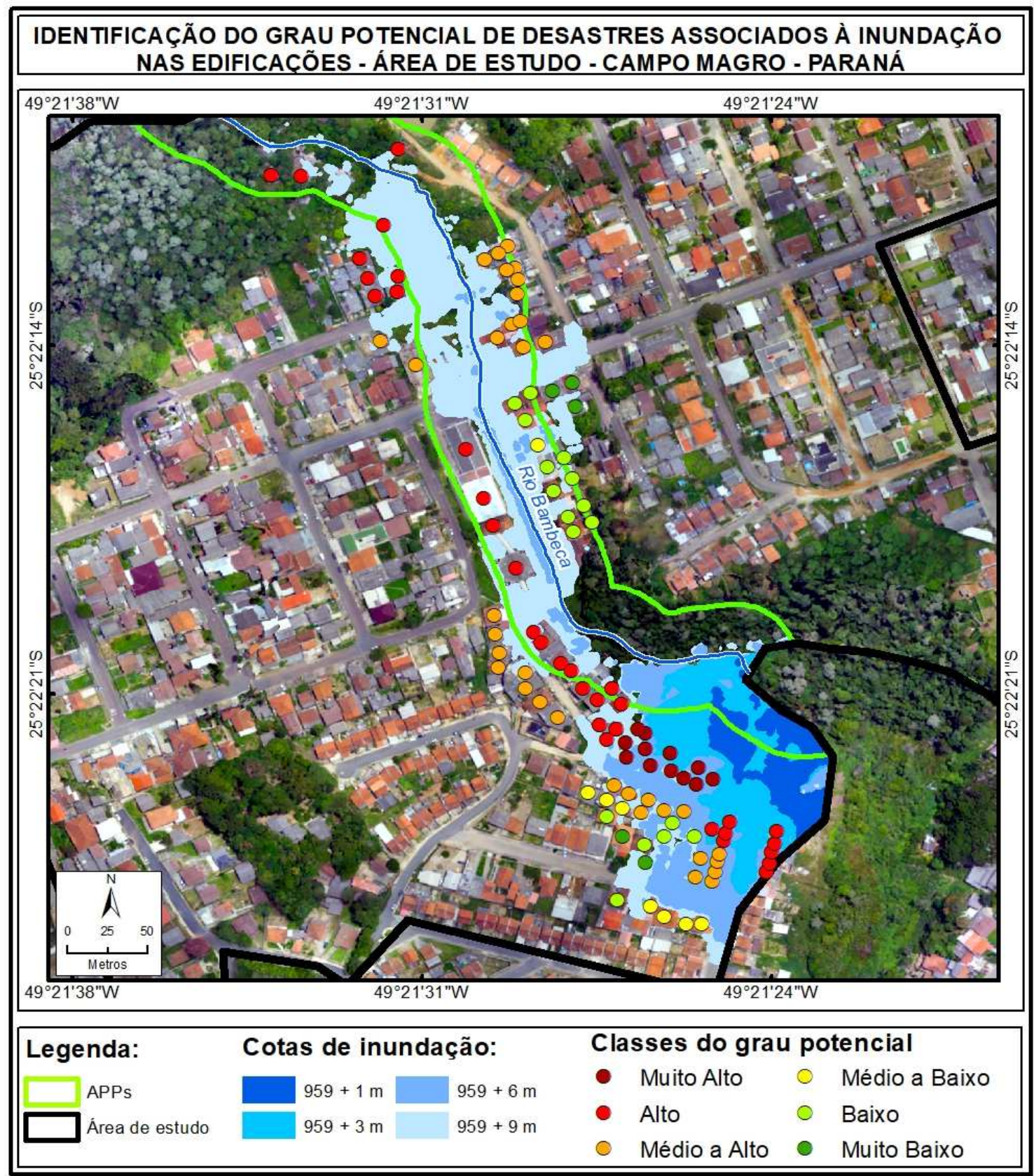

Figura 9: Área de inundação (Campo Magro/PR): mapeamento do grau potencial de desastres associados à inundação em áreas edificadas.

Essa análise permitiu constatar que a configuração espacial do grau potencial de desastres associados à inundação é complexa e dinâmica. Por exemplo, nesta área de estudo e nesse contexto, adotar como critério a remoção da população que ocupa a área de APP do rio Bambeca, de acordo a legislação brasileira, é uma importante medida, mas que não vai interferir diretamente na área prioritária de atenção frente aos desastres associados à inundação. 
Sendo assim, destaca-se a necessidade da realização de constantes estudos que auxiliem na execução dos processos de gestão do risco e de desastres associados à inundação, com implantação tanto de medidas estruturais, bem como estruturantes. As medidas estruturais, de acordo com Carneiro e Miguez (2011) são aquelas em que a paisagem é alterada pelo homem, como principal exemplo cita-se: a remoção (realocação) da população que habita a área de risco à inundação, por exemplo. Os mesmos autores destacam-se que as medidas estruturantes (não estruturais) são aquelas em que o homem aprende a conviver com o risco de inundação, como exemplos citam-se: construção de barreiras e elevação das estruturas existentes.

O mapeamento do grau potencial de desastres associados à inundação, a partir do cruzamento dos mapeamentos de risco e vulnerabilidade do lugar à inundação, demonstrou ser uma metodologia eficaz para auxílio na tomada de decisão frente aos processos de prevenção e mitigação de desastres associados à inundação.

De acordo com Gregorio et al. (2015, p.45) dentro do macroprocesso da gestão de riscos de desastres, as etapas de prevenção e mitigação revelam a execução

de estudos das ameaças, vulnerabilidades e cenários de risco; mapeamento de riscos e cadastramento de famílias em risco; plano municipal de redução de riscos; estruturação e operação de sistemas de monitoramento, alerta e alarme; medidas de mitigação não estruturais; medidas de mitigação estruturais.

Com isso, destaca-se que o uso de dados de sensoriamento remoto, coletados com VANT, têm apresentado um grande aumento nos últimos anos a nível mundial para avaliação das áreas com risco e desastres associados à inundação (ZHOU et al., 2000; MARINHO et al., 2012), entretanto, ainda são poucos e recentes os trabalhos que usam o VANT para aquisição desses dados no contexto brasileiro (LONGHITANO, 2010; BUFFON et al., 2017).

Desse modo, buscou-se com este trabalho reforçar o uso de VANT e apontar um encaminhamento metodológico para avaliação do risco e do grau potencial de desastres associados à inundação. Conforme apontam Sausen e Narvaes $(2015$, p.121) os dados provenientes de VANT "podem monitorar as águas de inundação, mapear as áreas que potencialmente podem ser afetadas e apoiar ações de prevenção, sendo possível utilizá-los de forma eficiente e operacional nas mais diversas fases da gestão de desastres de inundação". Em suma, é possível obter um mapeamento síntese do grau potencial de 
desastres associados à inundação, com base na identificação das áreas prioritárias de atuação para fins de planejamento e de intervenções imediatas.

\section{Conclusões}

Os passos adotados no encaminhamento metodológico referente ao processo de cruzamento dos mapeamentos de risco à inundação com o de vulnerabilidade do lugar a inundação, se mostraram eficientes para sintetizar as condições de exposição da população frente a ocorrência de desastres durante episódios de inundações. Os procedimentos para a construção dos mapeamentos são de baixo custo, permitindo sua aplicação em outras áreas de interesse.

O uso do VANT para aquisição dos dados apresentou como benefícios: 1) redução dos custos associados à aquisição de imagens aéreas; 2) maior flexibilidade na aquisição das imagens; 3) melhor resolução espacial e temporal se comparado ao uso de imagens de satélites gratuitas disponíveis para o Brasil; e 4) possibilidade de maior nível de desagregação dos dados.

Como principal limitação, cita-se a baixa autonomia no tempo de voo do equipamento, o que dificulta a execução de levantamentos para áreas acima de $1 \mathrm{~km}^{2}$ (tempo relativo a estimativa de área recoberta para cada carga completa da bateria - autonomia de voo).

Os resultados encontrados condizem com a realidade identificada em campo, permitindo afirmar que a área de estudo necessita de medidas de prevenção e mitigação frente a problemática de inundações. O trabalho revela, considerando a probabilidade futura de efetivação do cenário integral de risco à inundação, que 41,3 \% das edificações apresentam grau potencial de desastres associados à inundação na categoria de muito alto e alto e $31,2 \%$ apresentam grau na categoria médio a alto, totalizando $72,5 \%$ das edificações. É importante lembrar, que essa afirmação utiliza-se do resultado obtido a partir do risco de inundação com a vulnerabilidade do lugar a inundação.

Esses valores expressivos, demonstram que o uso e ocupação da terra nessa área não foi pautado em critérios de planejamento urbano que considere o ambiente (natural e social) 
de modo integrado. Ao analisar o mapeamento que apresenta o grau potencial de desastres associados à inundação em conjunto com a determinação da área de APP prevista em lei, observa-se que uma porção para além da APP é mapeada com risco de inundação e apresenta edificações com grau potencial de desastres associado à inundação nas categorias muito alto e alto. Nesse sentido, entende-se que a preservação e fiscalização da APP é de extrema importância para a gestão de riscos e de desastres associados à inundação, mas também, afirma-se a importância de estudos como este, a fim de que revelem áreas que não estão dentro da APP e necessitam de medidas de prevenção e mitigação.

Com isso, ressalta-se que a avaliação do grau potencial de desastres associado à inundação, deve pautar-se em características dos indivíduos, das sociedades, dos ecossistemas e dos sistemas tecnológicos, que quando integrados geram uma síntese que pode ser apresentada por meio de uma representação cartográfica (mapeamento) que visa auxiliar nas tomadas de decisões frente ao problema.

\section{Referências bibliográficas}

BUFFON, E. A. M. A leptospirose humana no AU-RMC (Aglomerado Urbano da Região Metropolitana de Curitiba/PR) - risco e vulnerabilidade socioambiental. Dissertação (Mestrado em Geografia) - Setor de Ciências da Terra, Programa de Pós-Graduação Geografia, Universidade Federal do Paraná, Curitiba, 2016, $171 f$.

BUFFON, E. A. M.; PAZ, O. L. S.; SAMPAIO, T. V. M. Uso de Veículo Aéreo Não Tripulado (VANT) para mapeamento das vulnerabilidades à inundação urbana: referenciais e bases de aplicação. Revista do Departamento de Geografia, Volume Especial - Eixo 9, 2017, p. 180-189, DOI: 10.11606/rdg.vOispe.132547.

CANALI, N; MURATORI, A. M. Síntese da evolução geomorfológica da bacia de Sedimentação de Curitiba. In: 3‥Simpósio Regional de Geologia. Curitiba. Sociedade Brasileira de Geologia. Núcleo de São Paulo; novembro, 1981, Atas, vol.2, 389p.

CARNEIRO, P. R. F.; MIGUEZ, M. G. Controle de inundações em bacias hidrográficas metropolitanas. São Paulo: Annablume, 2011.

CASTRO, C. M.; PEIXOTO, M. N. O.; RIO, G. A. P. Riscos Ambientais e Geografia: Conceituações, Abordagens e Escalas. In: Anuário do Instituto de Geociências - UFRJ. Rio de Janeiro: UFRJ, Vol. 28-2, 2005, p. 11-30.

CASTRO, A. L. C. Manual de planejamento em defesa civil. Vol.1. Brasília: Ministério da Integração Nacional/Departamento de Defesa Civil. 1999, 133p.

CIRILO, J. A. et al. Suporte de Informações Georreferenciadas de Alta Resolução para Implantação de Infraestrutura e Planejamento Territorial. Revista Brasileira de Geografia Física, v. 7, n. 4, 2014, p. 755-763, ISSN: 1984-2295.

CUNHA, L. Vulnerabilidade e Riscos Naturais: exemplos em Portugal. In: FREITAS, M. I. C. de.; LOMBARDO, M. A.; ZACHARIAS, A. A. Vulnerabilidades e riscos: reflexões e aplicações na análise do território. Rio Claro (SP): UNESP - IGCE-CEAPLA, 2015, p.55-62.ISBN: 978-85-89082-42-6.

CUTTER, S. L. Vulnerability to environmental hazard. Progress in Human Geography, v. 20, n.4, 1996, p.-529539. 
DANTAS, C. E. O. Previsão e Controle de Inundações em Meio Urbano com Suporte de Informações Espaciais de Alta Resolução. Tese (Doutorado em Engenharia Civil), UFPE, Programa de Pós-Graduação em Engenharia Civil, Universidade Federal Pernambuco, Recife, 2012, 221p.

DAUPHINÉ, A. Risques et catastrophes - Observer, spatialiser, comprendre, gerer. Paris: Armand Colin, 2001. ISBN: 2-200-25042-8.

GREGORIO, L. T.; SAITO, S. M.; SAUSEN, T. M. Sensoriamento remoto para a gestão de risco de desastres naturais. In: SAUSEN, T. M. \& LACRUZ, M. S. P. Sensoriamento Remoto para desastres. São Paulo: Oficina de Textos, 2015, p. 43-67. ISBN: 978-85-7975-175-2.

FENG, Q; LIU, J; GONG, J. Urban flood mapping based on unmanned aerial vehicle remote sensing and random forest classifier-A case of Yuyao, China. Water, v. 7, n. 4, 2015, p. 1437-1455, DOI: 10.3390/w7041437.

FLORENZANO, T. G. Geotecnologias na geografia aplicada: difusão e acesso. Revista do Departamento de Geografia, v.17, 2005, p. 24-29, ISSN 2236-2878

HAN, J-G.; KIM, S-P. Inundation Vulnerability Zone Mapping of Urban Coastal Area using High Spatial Resolution Data (Airborne LiDAR) and GIS Spatial Analysis. Journal of Coastal Research, n. 64, 2011, p. 1681, ISSN: 0749-0208.

IBGE. Instituto Brasileiro de Geografia e Estatística. Mapas temáticos: Clima (1998). Disponível em: <ftp://geoftp.ibge.gov.br/mapas_tematicos/mapas_murais/clima.pdf>. Acesso em: setembro de 2017.

JUSTINIANO, E. F. Registro fotográfico. In: VENTURI, L. A. B. (org.) Praticando Geografia: técnicas de campo e laboratório em geografia e análise ambiental. São Paulo: Oficina de Textos, 2009, p. 187-195.

KOBIYAMA, M. et al. Prevenção de desastres naturais: conceitos básicos. Curitiba, PR: Ed. Organic Trading, 2006. 109 p.

LONGHITANO, G. A. VANTS para sensoriamento remoto: aplicabilidade na avaliação e monitoramento de impactos ambientais causados por acidentes com cargas perigosas. Dissertação (Mestrado em Engenharia). Escola Politécnica. Universidade de são Paulo, 2010, 148 p.

MARINHO, R. R.; PARADELLA, W. R.; OLIVEIRA, C. G.; SILVA, A. Q.; SANTOS, A. R. Aplicação de imagens SAR orbitais em desastres naturais: mapeamento das inundações de 2008 no vale do Itajaí, SC. Revista Brasileira de Cartografia, n.64/3, 2012, p. 317-330, ISSN: 1808-0936.

PEREIRA, A.; GOMES, A.; ALBERTI, A. Vantagens da utilização de dados ALS (LiDAR) na caracterização morfológica das vertentes costeiras da Galiza (Espanha): aplicação ao setor de Mougás. Revista de Geografia e Ordenamento do Território (GOT), n. 4 (dezembro). Centro de Estudos de Geografia e Ordenamento do Território, 2013, p. 223-248. http://dx.doi.org/10.17127/got/2013.4.010

REBELO, F. Geografia Física e Riscos Naturais. Coimbra: Imprensa da Universidade de Coimbra, 2010. ISBN: 978-989-26-0054-3.

SAUSEN, T. M.; NARVAES, I. da S. Sensoriamento remoto para inundação e enxurrada. In: SAUSEN, T. M. \& LACRUZ, M. S. P. Sensoriamento Remoto para desastres. São Paulo: Oficina de Textos, 2015, p. 119-148. ISBN: 978-85-7975-175-2.

SILVEIRA, W. N.; KOBIYAMA, M.; GOERL, R. F.; BRANDENBURG, B. História das inundações em Joinville (18512008). Curitiba, PR: Organic Trading, 2009. 153 p.

TOMINAGA, L. K. Desastres Naturais: por que ocorrem? In: TOMINAGA, L. L.; SANTORO, J.; AMARAL R. do (orgs.). Desastres naturais: conhecer para prevenir. 3a ed. - São Paulo: Instituto Geológico, 2015, p. 1124.ISBN: 978-85-87235-09-1.

TUCCI, C. E. M. Inundações e drenagem urbana. In: TUCCI, C. E. M. \& BERTONI, C. (Orgs.). Inundações urbanas na América do Sul. Porto Alegre, RS: Associação Brasileira de Recursos Hídricos, 2003.

UNISDR - UNITED NATIONS INTERNATIONAL STRATEGY FOR DISASTERS REDUCTION. Terminology on disaster risk reduction. Geneva, 2009. Disponível em < http://www.unisdr.org/we/inform/publications/7817>, acesso em 24 de abril de 2017. 
ZHOU, C.; LUO, J.; LI, B. Flood monitoring using multi-temporal AVHRR and RADARSAT imagery. Photogrammetric Engineering e Remoto Sesing, v. 66, n. 5, May 2000, p.633-638, ISSN : 0099-1112.

WOLMAN, M. G. A cycle of sedimentation and erosion in urban river channels. Geog. Annaler, v. 49A, 1967, p. 385-395, ISSN: 1468-0459. 